\title{
Summer STEM Course Gone Viral: A Virtual Curriculum Development
}

\section{Grant MacKinnon ( $\nabla$ grant.mackinnon@vanderbilt.edu )}

Vanderbilt University School of Medicine https://orcid.org/0000-0002-5363-9428

Kyle Langford

Vanderbilt University School of Medicine

Holly Harper

Vanderbilt University School of Medicine

Kelsei Brown

Vanderbilt University School of Medicine

Sushmitha Divakar

Vanderbilt University School of Medicine

Mollie Limb

Vanderbilt University School of Medicine

Louise Alexander

Vanderbilt University Medical Center

Charlotte Brown

Vanderbilt University Medical Center

\section{Short Report}

Keywords: STEM, summer programs, virtual programs, enrichment programs, online learning

Posted Date: October 19th, 2020

DOI: https://doi.org/10.21203/rs.3.rs-93264/v1

License: (c) (i) This work is licensed under a Creative Commons Attribution 4.0 International License.

Read Full License 


\section{Abstract}

Due to the COVID-19 pandemic, a high school academic summer course concentrated in medicine was converted from a three-week on-campus experience to a two-week virtual course. While attending a residential summer course may be a barrier for some students, a virtual program may provide an equally rigorous and rewarding experience.

\section{Manuscript}

University-run high school academic summer programs have demonstrated effectiveness in increasing student interest in pursuing a career in science and medicine. [1,2] Many regional and national organizations, such as the National Science Foundation, have established initiatives to increase access to these programs.[3] One such program is Vanderbilt University's Program for Talented Youth (PTY), founded in 2000 and dedicated to providing accelerated inquiry-based educational opportunities to serve the needs of gifted students. This immersive on-campus three-week program typically offers twelve to fourteenunique courses, including one concentrated on medicine, and attracts several hundred middle and high school students annually. In light of the COVID-19 pandemic in the spring of 2020, on-campus programs were no longer feasible, so PTY adapted the medicine course to an entirely virtual format. The virtual course aimed to offer the same intellectual demands and community traditionally afforded by PTY programs despite the changing circumstances.

The two-week virtual medicine course was offered in June 2020 and enrolled seventeen high school students ranging in age from fifteen to eighteen years. Students were of a geographically diverse background with representation from eleven states and two countries. PTY application requirements included an ACT, SAT, or PSAT exam with more than one categorical score above the $95^{\text {th }}$ percentile. Six senior medical students and two faculty advisors designed and instructed the course. A detailed schedule of activities is found in Table 1.

Table 1. Virtual course weekly schedule.

$\mathrm{CBL}=$ case-based learning; $\mathrm{LC}=$ learning communities; TBL $=$ team-based learning

\begin{tabular}{|c|c|c|c|c|c|}
\hline \multicolumn{7}{|c|}{ Week 1 - Cardiovascular Disease } \\
\hline Central Time & Monday & Tuesday & Wednesday & Thursday & Friday \\
\hline 10 a.m. -11 a.m. & Orientation & Panel & Lecture & Panel & LC \\
\hline 11 a.m. -12 p.m. & Lecture & Lecture & CBL & Lecture & Lecture \\
\cline { 1 - 3 } & Lecture & CBL & & Simulation & Panel \\
\hline
\end{tabular}

\begin{tabular}{|c|c|c|c|c|c|}
\hline \multicolumn{7}{|c|}{ Week 2 - Infectious Disease } \\
\hline Central Time & Monday & Tuesday & Wednesday & Thursday & Friday \\
\hline 10 a.m. -11 a.m. & Panel & Panel & Lecture & Lecture & Panel \\
\hline 11 a.m. -12 p.m. & Lecture & Lecture & CBL & TBL & Capstone Project \\
\hline 12 p.m. -1 p.m. & Demonstration & CBL & & & \\
\hline
\end{tabular}


Table Legend.

$$
\begin{array}{|c|}
\hline \text { Large group lectures } \\
\hline \text { Large group activities } \\
\hline \text { Small group activities } \\
\hline
\end{array}
$$

The virtual course included assorted synchronous learning activities scheduled Monday through Friday from 10 a.m. to 1 p.m. Central Time on a video conferencing platform. In line with Vanderbilt's Protection of Minors policy, access to the platform was privacy protected and instructors completed an online Protection of Minors course. In addition, any email communication with students required all instructors to be addressed.

Each week was designed around a central theme: cardiovascular conditions in week one and infectious diseases in week two. Synchronous activities included lectures, case-based learning, team-based learning, learning communities, simulations, and panel discussions with medical students and faculty. A short break was provided between synchronous activities. Daily asynchronous learning activities included instructional videos, review articles, textbook chapters, podcasts, practice guidelines, and completion of a written reflection. Instructors were available in virtual weekday "office hours" from 2 p.m. to 4 p.m. to answer questions or provide guidance. An anonymous feedback form was available online for students to offer suggestions for improvement.

Each case-based learning activity encompassed two days and opened with an instructor-led small group review of a clinical case report and subsequent creation of learning objectives. Students were expected to research the learning objectives independently in preparation for small group discussions the following day. Team-based learning began with students collectively completing a quiz in small groups without instructors. The quiz answers were revealed and reviewed once the large group reconvened. The latter portion of team-based learning included small group presentations on assigned topics pertaining to the quiz material. Learning communities was an informal small group forum for students and instructors to discuss the sociologic and public health impacts of the opioid epidemic.

While the in-person course conventionally offers students experience in the hospital, clinic, and operating room settings, the virtual course utilized simulation as an experiential learning interface. Students viewed a recorded cardiac arrest simulation and observed a live demonstration of airway equipment and ultrasound-guided intravenous access in an operating room. The course included panel discussions focused on the varied pathways to medical school, career opportunities, and dual-degrees programs.

The course concluded with a capstone project. Each small group was assigned a debate topic and divided into two teams to represent countering perspectives on the issue. Topics included mandatory versus encouraged social distancing, pass/fail USMLE Step 1 reporting, and the widespread use of antibiotics in uncomplicated urinary tract infections. Pre- and post-debate polls from the observing 
students were completed. Student families were invited and encouraged to attend the debates and a course recap on the final day.

To help promote community and vulnerability, the course integrated entertaining questions and polls at the beginning of many activities. PTY held four optional evening activities in conjunction with other PTY virtual courses. Two evening activities were educational seminars on the college admission process whereas the other two activities included virtual games and icebreakers.

This program demonstrated that a virtual format for summer academic programs is feasible and may provide greater access. While most programs provide financial aid, high school students and families may welcome virtual programs as an alternative means of challenging gifted students with rigorous academics and fostering community.

\section{Declarations}

Funding: none

Conflicts of Interests/Competing Interests: On behalf of all authors, the corresponding author states that there is no conflict of interest.

Availability of data and material: not applicable

Code availability: not applicable

\section{References}

1. Kitchen JA, et al. The impact of college- and university-run high school summer programs on students' end of high school STEM career aspirations. Science Studies and Science Education. 2018;102(3):529-547.

2. Kim, M. (2016). A Meta-Analysis of the Effects of Enrichment Programs on Gifted Students. Gifted Child Quarterly, 60(2), 102-116.

3. White House. Charting a course for success: American's strategy for STEM education. 2018. 